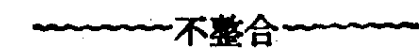

震旦紀(?)千枚岩

五、渒河、史河流域前震旦紀地居

(1) 大別山(杂岩)系

mำm不整合

（2）俳子岭系

厚 1,000 米

分 5 層。
1. 大理岩虔

2. 石英岩展

3. 石英片岩層

4. 云母片破居

5. 千枚岩居

六、地首对比

七、几点新認識

\begin{tabular}{|c|c|c|c|c|c|c|}
\hline 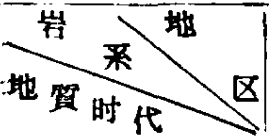 & 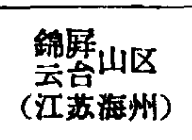 & $\begin{array}{c}\text { 局山区 } \\
\text { 年山地 } \\
\text { (江苏东海) }\end{array}$ & 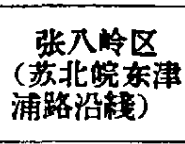 & $\begin{array}{l}\text { 宿 松 区 } \\
\text { (安数酮南) }\end{array}$ & 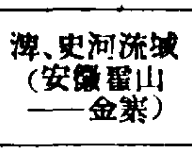 & 㢼 \\
\hline $\begin{array}{l}\text { 元 } \\
\text { 古 } \\
\text { 代 }\end{array}$ & $\begin{array}{l}\text { 云 } \\
\text { 台 } \\
\text { 系 }\end{array}$ & $\begin{array}{l}\text { 房房豈 } \\
\text { 山花入 } \\
\text { 蓝 }\end{array}$ & 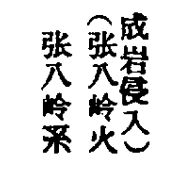 & 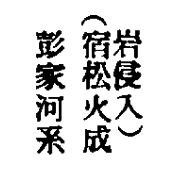 & 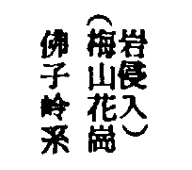 & $\begin{array}{l}\text { Temiskaming } \\
\text { (Algoman 化 } \\
\text { 融䋆度入) }\end{array}$ \\
\hline $\begin{array}{l}\text { 太 } \\
\text { 古 } \\
\text { 代 }\end{array}$ & 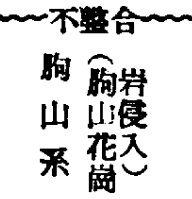 & & & 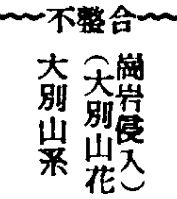 & 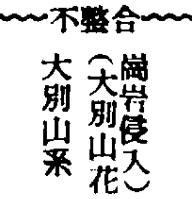 & 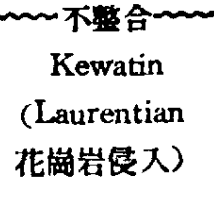 \\
\hline
\end{tabular}

1. 沉积特点的新認識: 斯特拉霍夫院士在他的名 著地史学原理中說到: “前寒武䄫的沉积特点,首先引 起注学的是盐、煤、磷酸盐等类……在前寒武紀中完 全沒有，仅在下寒武紀才开始出現……前寒武紀目前 还沼有找到磷筫岩石(磷灰岩)”。“釷和鎂的碳酸盐的 情况虽然很有意义，但可惜闻明得还極不清管”。最近 国內出版的王鴻槕著“地史学数程”以及苏联大百科全 書中也有相似的說法; 由于本区工作的嵝果，以上問 題似有更正之必要。磷酸盐类在前寒武紀即已大量存 在，此外鉐与鉄的碳酸盐类也是本区的重要岩居，因 此我們对这些沉积特点应予以应有的重悓。

2. 前寒武紀造山旋迴的新認識: 橫汲清在他的名 著“中国主要地質构造单位”中說到: “虽然我椚相信 在中国各个地区有朤寒武紀的造山輪廻（或很多浩山 輸佪), 但是由于五台系不能从泰山杂岩系有时甚至 不能从震旦采分別开来, 所以这項工作未曾得到良好 的結果”。現在由于喥現錦屏統底部砾石片岩的存在, 且云台、胸山二系可以很好地分开，同时大別山系与 彭家河系有極其不阁的岩性美异，上下層位显然有別， 虽然份未找到涩意的不整合面，但代表两个地質时期 是絕無疑問的; 又因为张八岭系不整合于震旦紀灰岩 之下，因之，我們对前寒武紀浩山旋廻至少可确定有 三个亚雄自:

$$
\begin{aligned}
& \text { 亚徒走名一一一胸山片麻岩以前 } \\
& \text { 亚旋趣二一一錦屏絰底部砾石片岩以前 } \\
& \text { 亚旋廻三一一震旦紀灰岩以解 }
\end{aligned}
$$

3. 合磷地居的新認識: 由于大別山磷研”的發現, 使我們相信在相同首位的前震旦系中有㜊現磷矿的可 能，因此有展开普查找矿的必要。
八、問題与尾語 过去中国标准的前震旦系，所 謂溙山系、五台系、榩沦系等分居对比問題，久無統 一見解。襄于以上锗系尚有疑义，因而本交所进的的 震旦系不与华北作硬性的对比。但据苏皖二省的战况 来看，泰山、五台二系的代表地層可能均有存在，哅 山系及大別山系均相当于泰山系，而云台系及彭家 河系均相当于五台系, 由于不整合面的存在, 前者

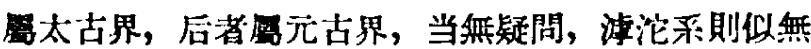
發現。

张 鑑 模

(北京大学耵留地理采)

1958 年 1 月 13 日

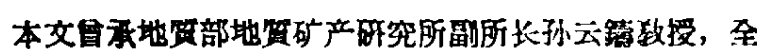

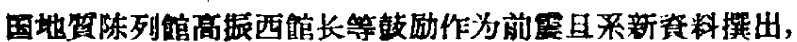
以便抛砖引王获得討論修正.

\section{天山阿尔泰山系山前地形反 旋生成作用的个案傾向計算}

天山阿尔泰山系的迎風面可以形成相 当强 的 正 变高区，在科压（屏䊅）大气中 $U_{0}=5 /$ 秒的均匀开 風下这正变高在下首, 例如 $700 \mathrm{mb}$ 上, 可以大到 $40-60$ 米/12 小时[1]。

这里我門計算一个个案的㑯向分布說明这种正变 高所起作用的重要。例子是 1957 年1月 26 日 15 国 际时的(圖 1)。由 25 日到 27 日西边来的一个高空牛 淺的大槽移到天山阿尔泰山迎風区就很块減弱，井 且在 $700 \mathrm{mb}$ 以下各首生成了一个小高压。

計算方法与过去 ${ }^{[1,2]}$ 相像*。先取在上界的垂㨁 


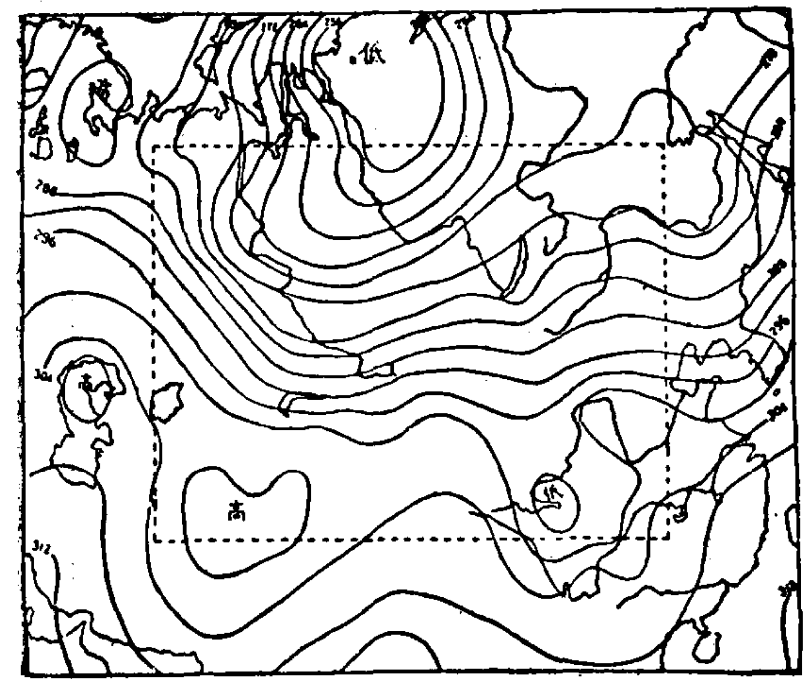

国 1957 年 1 月 26 日（15Z） $700 \mathrm{mb}$ 国， 高庋单位: 位势 10 米。

运动， $\omega=0$, 在下界 $\omega_{0}=\frac{1}{g} \rho v_{0} \cdot \nabla h$, 解 $\omega$ 的三維拉 普拉斯方程来求地形的 $\omega$, 再由 $\Delta \omega / \Delta p$ 求地形扰的

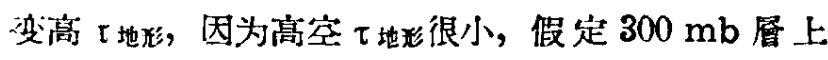

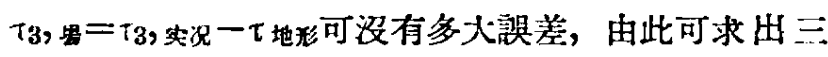
首模式中 $700 \mathrm{mb}$ 及 $500 \mathrm{mb}$ 汥有地形时温压場本身 的傾向 $\tau_{1}$ 及 $\tau_{5}$ 。比較经愿中 $\tau$ 堨及 $\tau$ 地的大小扭与 低愿实际傾向場比較就可了解非形扰动的大小和所起 的作用。

实际計算中取 $\Delta x=\Delta y=400$ 公里, $2 \Delta p=200 \mathrm{mb}$ 。 用最接近一曆空空圆 $(850,700,500 \mathrm{mb})$ 上地轉風的 一牛作为 $v_{0}$ 。地形出均气压高度与[1]中所用相同。 解 $\omega$ 地形的用的是不等距三維网格上的張弛法。在場 的变高計算中仍假定 $\omega_{3}$ 場 $=\frac{1}{2} \omega_{6}$ 場, $a_{4}=1, a_{6}=2$, 义 $\sigma=0.5 /$ 十位势末。三維張弛法中下層地形边界上 的值由上留絕热方程向下推算求出。傾向实况用由前 后 12 小时殺录求得的 24 小时变高来代表。

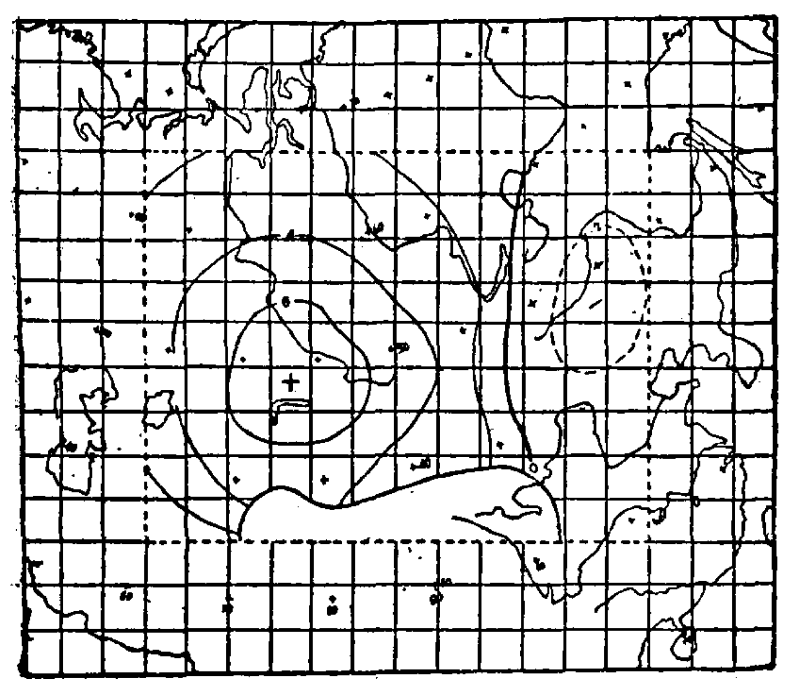

121957 年1月 26 日 $(15 \mathrm{Z}) 700 \mathrm{mb}$ 上地形扰动

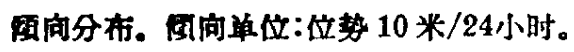

計算結果愣地形变高在 $300 \mathrm{mb}$ 面上只有 40 米/24 时,但在 $700 \mathrm{mb}$ 上已才到 70 米/24 小时。900 $\mathrm{mb}$ 上是 100 米/24 小时, 大小与过去的估計[1]相近。 $700 \mathrm{mb}$ 上正变高中心位置在巴尔喀什湖以北，貝加尔 湖以东是負变高区 (圖 2 )。700 $\mathrm{mb}$ 温压場的变澺分 布在巴尔喀什湖附近是負变高区(圆略)，所以只有把 地形扰动活成的变高加起来之后 (圖 3 ), 才会得到这 区域付近实际覌測到的巨大正变高（圖 4)。这可以 説明这例子中这区域里高空槽的惐弱和小高压的生成 可能是具体地形条件下运动学限制的結果

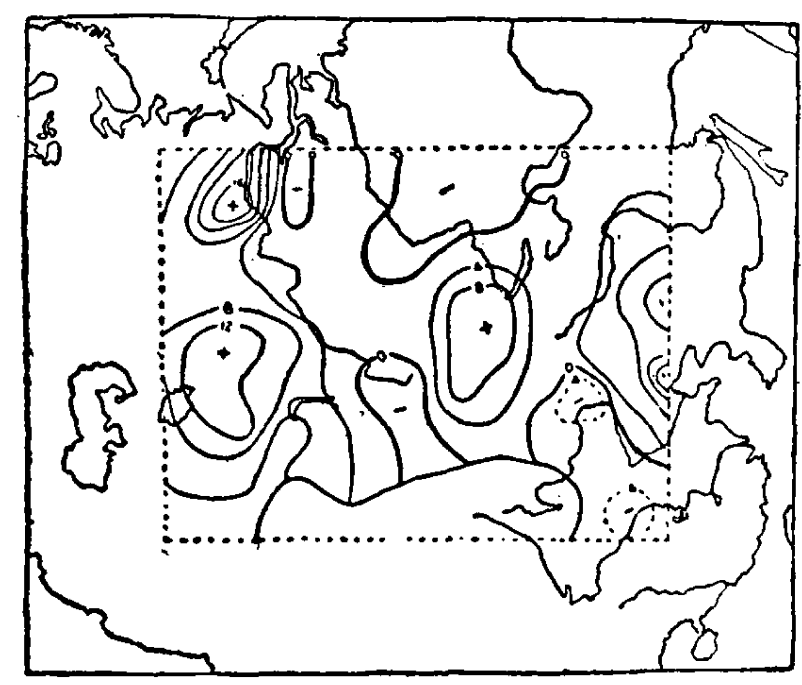

四 31957 年 1 月 26 日 (15Z) $700 \mathrm{mb}$ 算得总等 向。单位同圆 1 .

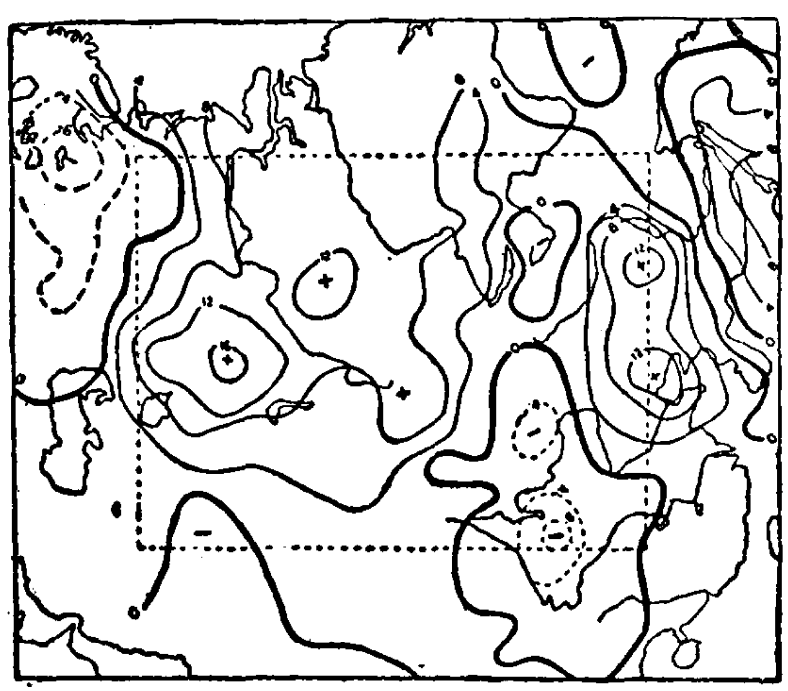

41957 年1月26日 $(03 \mathrm{Z})$ 到 27 日 $(03 \mathrm{Z}) 700 \mathrm{mb}$ 上实你变高。单位同国 1 。

赵明哲 䃆晨潮

(北京大学物理杀)（中国科学院地球物理研究所） 1957 年 11 月 23 日

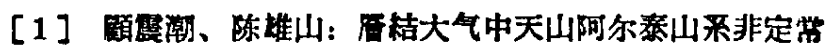

- 注意[2]中 $\Delta \tau_{0}$ 式中 $a_{0} / 2$ 应作 $a_{\text {。 }}$ 
扰动的分布，样学通报，1957，378一379。

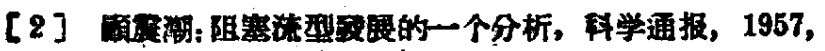
$215-216$.

\section{三厘米波段宿振吸收式隔离器}

鉄冾等磁物已越来越广泛地运用在微波領域中， 它在外加磁場的作用下呈現非互易的性能，能制成各 种非互易的微波元件，隔离器是其中最有用的一种。 隔离是指电䂭波在波导中正方向传銢衰减很小，反方 向传輸則裹减很大。隔离作用可以用不同的方法获 得, 可以利用鉄磁共振現象对徽波信号非互易的吸 收，也可以利用波导中橫械面內非互易的場移，又可 以用法拉第旋轉效应等方法。用第一种方法制成的隔 离器, 称为諧振吸收式隔离器, 它的主要优点是䊅构 簡单。在实驗空里我們制造了一个性能佾使人滿意的 三厘米波段的諧振吸收式隔离器。

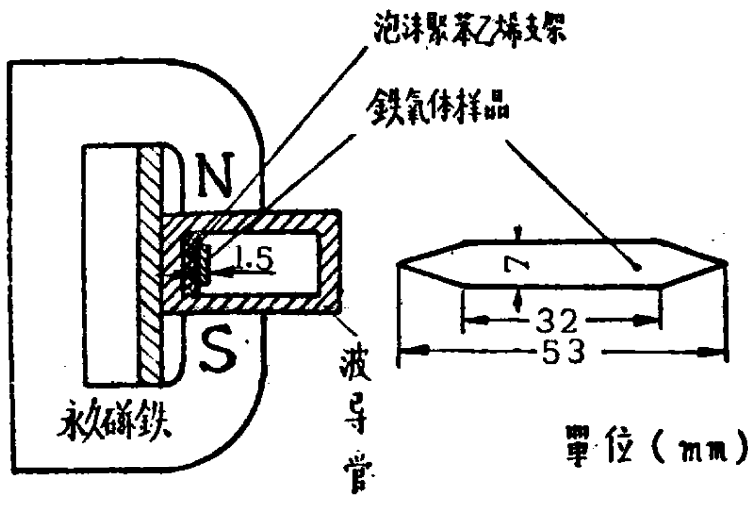

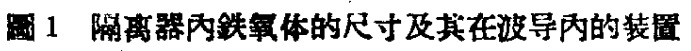

我們試制的諧振吸收式隔离器中所用的鉄冾等片 如圖 1 所示, 其成份为 $\mathrm{Mn}_{0.2} \mathrm{Mg}_{0.8} \mathrm{Fe}_{2} \mathrm{O}_{4}$, 鉄㓌氧片 平行于矩形波导狹面，外加磁場垂直于波导宽面，用 介电常数 $\varepsilon \approx 1.2$ 而衰耗極小的介質泡沫聚荣乙狶来支 持該片。在磁場作用下鉄冾氧的磁导深 $\mu$ 是一张量, 在垂直于外加磁場什面內的正圆極化波和負圆極化波 具有不同的 $\mu$ 值, 分別为 $\mu_{+}$和 $\mu_{-}$。当磁共振时 $\mu_{+}$有一峰值，在峰值时鉄㓌氧对于正国極化波的吸 收达最大值, 而它对于保圆極化波吸收很小，抹且沒 有峰值。在理想情况的正向传输时，波导中鉄梌氧样 品所在地点的高頻磁場为負国極化矢量, 所以衰减 很小，如果使外加磁場接近于鉄磁諧振磁場，反问传 的时, 該处的高頻磁場則为正圆極化矢量, 故塞减很 大，然而当波导中放入鉄梌氧片之后，由于它的介电 常数 $\varepsilon$ 与磁导淶 $\mu$ 都相当大, 因而能量向片內集中,

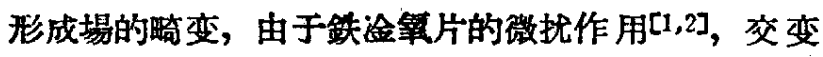
內磁場将不是一純圆極化波，因而对于反向与正向传

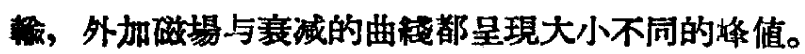
可是在波导中仍然可以找到一个最佳的位置，使反向
传輅褰减很大（共振磁場附近塞减达最大值）, 而使正 向传軨衰减也非常小，且其赛减的埄值出現在远离反 向传磁共振磁場的地方，如圖2所示。这样就有一个

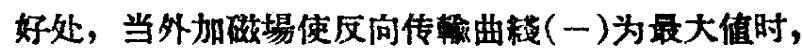

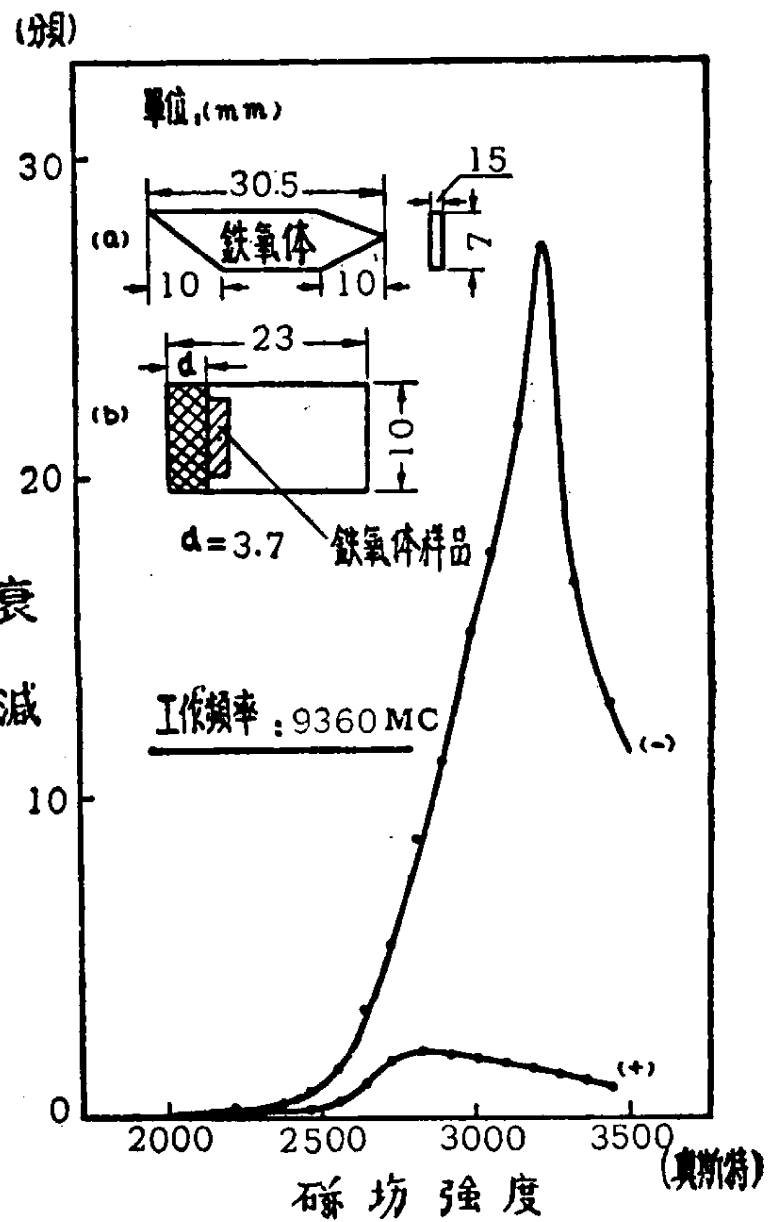

回 2 铁氧体在磁塔强度变化时的衰娍特性

正向传輸的害减很小，因而反问与正问善减之比最大。

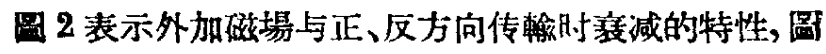
（a）表示鉄㓌氧样品的尺寸，圖（b）是它在波导中的 位置。为了提高測量的准确度，实驗时仅用隔窉器中 所用鉄冾氧片之一牛。从曲䋘中可以不到最住磁場約 为 3300 奥斯特, 这时反向一正向亲减之比为 22 (以分 Elitio

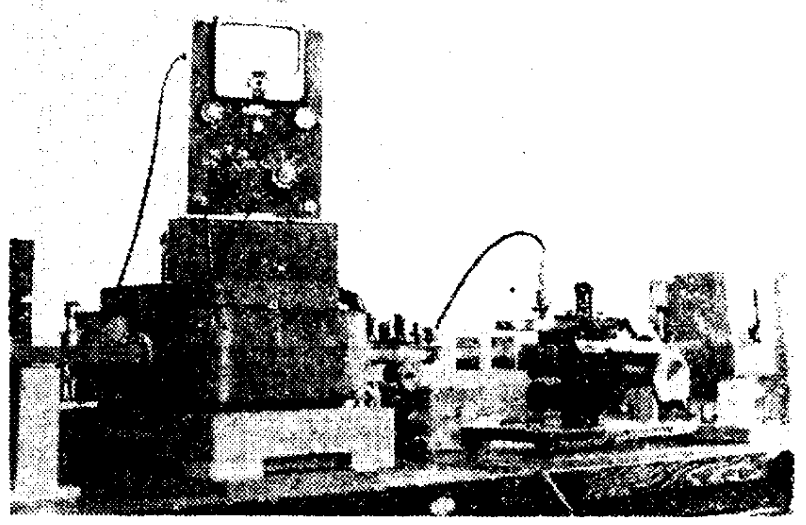

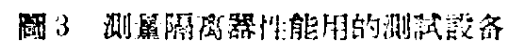

